\title{
Plasma Arc Cutting Dimensional Accuracy Optimization employing the Parameter Design approach
}

\author{
John Kechagias ${ }^{1, *}$, Markos Petousis ${ }^{2}$, Nectarios Vidakis ${ }^{2}$, and Nikos Mastorakis ${ }^{3}$ \\ ${ }^{1}$ TEI Thessaly, Mechanical Engineering Department, 41110 Larissa, Grecee \\ ${ }^{2}$ TEI Crete, Mechanical Engineering Department, 71004 Heraklion, Crete, Greece \\ ${ }^{3}$ Technical University of Sofia, Department of Industrial Engineering, Sofia, Bulgaria
}

\begin{abstract}
Plasma Arc Cutting (PAC) is a thermal manufacturing process used for metal plates cutting. This work experimentally investigates the influence of process parameters onto the dimensional accuracy performance of the plasma arc cutting process. The cutting parameters studied were cutting speed $(\mathrm{mm} / \mathrm{min})$, torch standoff distance $(\mathrm{mm})$, and arc voltage (volts). Linear dimensions of a rectangular workpiece were measured after PAC cutting following the full factorial design experimental approach. For each one of the three process parameters, three parameter levels were used. Analysis of means (ANOM) and analysis of variances (ANOVA) were performed in order for the effect of each parameter on the leaner dimensional accuracy to be assessed.
\end{abstract}

\section{Introduction}

Plasma-Arc Cutting (PAC) is a thermal manufacturing process used for processing various electrical conducting materials, such as carbon steel, stainless-steel, aluminium, cast iron and non-ferrous metals [1-3]. PAC mechanism (Fig. 1) is characterized by an electric arc established between the electrode and the workpiece. The electrode acts as the cathode, and the workpiece material acts as the anode in the process.

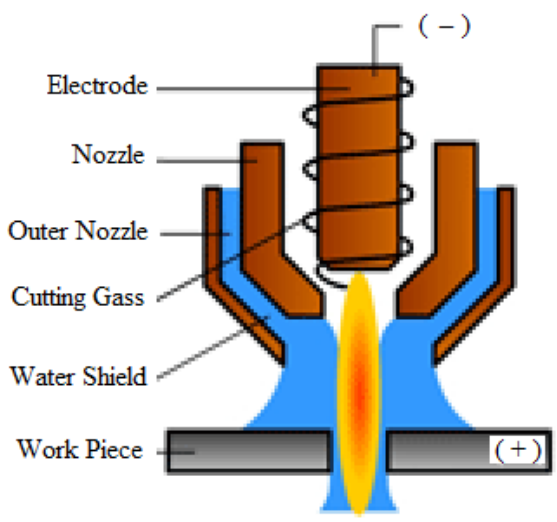

Fig. 1. Plasma-arc cutting mechanism.

Other thermal processes which are antagonistic to the PAC are the laser beam machining process (LMP) and the flame cutting. Selecting the most suitable process for industrial applications depends on several factors such as the type of the material, the layer thickness, the cutting speed, the quality indicators of each process and the cost. Plasma arc cutting can be used for the cutting of metal plates with thickness varying from 5 to $40 \mathrm{~mm}$ (Fig. 2).
The multi-parameter optimization of the PAC process according to quality indicators, such as the kerf characteristics, the dimensional accuracy and the quality of the cut surface has been experimentally studied by several researchers in several materials and experimental regions [3-11].

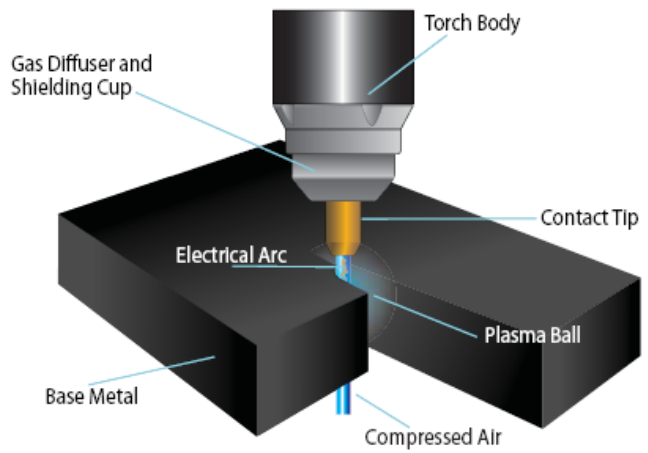

Fig. 2. Plasma Arc Cutting (PAC) process.

The current research work investigates the influence of plasma-arc cut process parameters onto the dimensional accuracy of St37 mild steel workpieces. A multi-parameter optimization was carried out using the full factorial design of experiments method.

\section{Parameter Design}

In this work experiments were conducted on St37 carbon steel (mild steel), which is widely used for industrial applications. The Yildirim CNC cutting machine was employed having a Burny phantom MCU and HPR 260

\footnotetext{
* Corresponding author: jkechag@teilar.gr
} 
air gas torch (Fig. 3). All experiments were performed in $16 \mathrm{~mm}$ thickness sheets (Fig. 4).

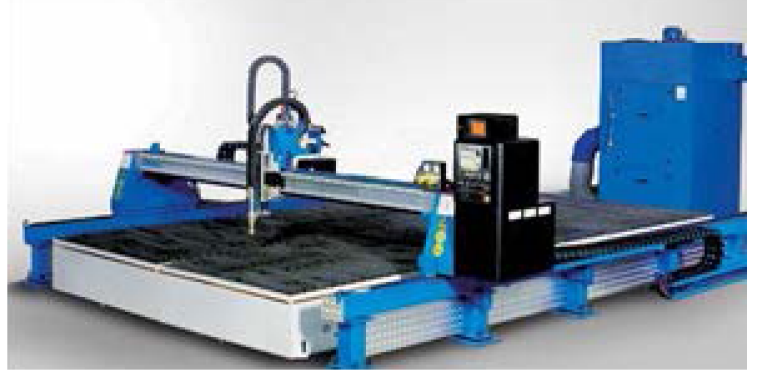

Fig. 3. CNC plasma arc cutting machine (Yildirim).

A three parameter full factorial design method was implemented (Table 1). Columns A, B, and C, are assigned to cutting speed $(\mathrm{mm} / \mathrm{min})$, torch standoff distance $(\mathrm{mm})$ and arc voltage (Volt), respectively.

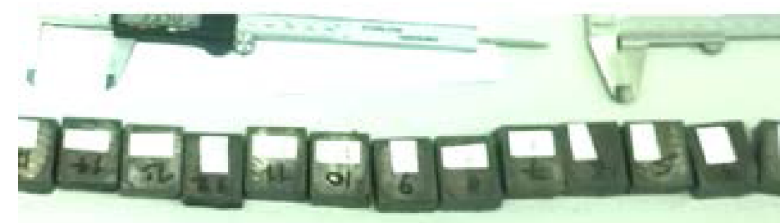

Fig. 4. Workpieces (rectangle shape: $30 \mathrm{mmX} 40 \mathrm{mmX} 16 \mathrm{~mm}$ ).

A $30 \mathrm{mmx} 40 \mathrm{~mm}$ rectangular cut was performed for all 27 combinations as indicated in the orthogonal matrix of the experiment (Table 1). Clockwise (CW) cut direction was followed in all experiments.

The leaner $\mathrm{X}$ dimension of the rectangular workpiece was measured on its top surface (Fig. 5). For each workpiece the average of five measurements as well as the deviation (maximum minus minimum value of the five measurements) were calculated during this work.

The measurements were taken along the $\mathrm{X}$ direction using a 1 micron accuracy digital calliper.

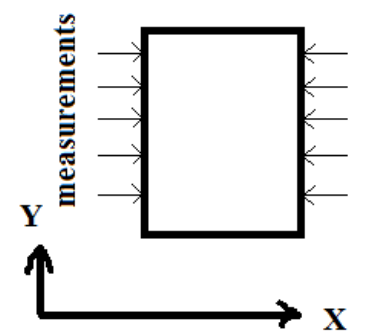

Fig. 5. Direction of measurements

\section{Data Analysis}

\subsection{Analysis of Means - ANOM}

After all the experiments were conducted and measured, an analysis of means (ANOM) was performed onto the experimental results (Table 2 and 3) and relevant diagrams were exported (Fig. 6 and 7) in order to optimize the process according to the Leaner Dimension and the minimum deviation of the leaner dimensions criteria.

Table 1. Experimental cases studied.

\begin{tabular}{|c|c|c|c|c|c|}
\hline & A. & B. & C. & & \\
\hline No & $\begin{array}{c}\text { Cutting } \\
\text { Speed } \\
(\mathrm{mm} / \mathrm{min})\end{array}$ & $\begin{array}{c}\text { Torch } \\
\text { Standoff } \\
\text { Distance } \\
(\mathbf{m m})\end{array}$ & $\begin{array}{c}\text { Arc } \\
\text { Voltage } \\
\text { (Volts) }\end{array}$ & $\begin{array}{c}\text { Average } \\
\text { X } \\
\text { mm }\end{array}$ & $\begin{array}{c}\text { Dev } \\
(\max - \\
\text { min) } \\
\text { mm }\end{array}$ \\
\hline 1 & 2000 & 3 & 145 & 39.14 & 0.26 \\
\hline 2 & 2000 & 3 & 150 & 39.114 & 0.35 \\
\hline 3 & 2000 & 3 & 155 & 38.938 & 0.25 \\
\hline 4 & 2000 & 3.6 & 145 & 38.926 & 0.81 \\
\hline 5 & 2000 & 3.6 & 150 & 38.816 & 0.22 \\
\hline 6 & 2000 & 3.6 & 155 & 38.962 & 0.33 \\
\hline 7 & 2000 & 4.2 & 145 & 39.356 & 0.49 \\
\hline 8 & 2000 & 4.2 & 150 & 39.136 & 0.37 \\
\hline 9 & 2000 & 4.2 & 155 & 39.078 & 0.61 \\
\hline 10 & 2600 & 3 & 145 & 39.29 & 0.25 \\
\hline 11 & 2600 & 3 & 150 & 39.654 & 0.11 \\
\hline 12 & 2600 & 3 & 155 & 39.5 & 0.45 \\
\hline 13 & 2600 & 3.6 & 145 & 39.714 & 0.4 \\
\hline 14 & 2600 & 3.6 & 150 & 39.432 & 0.43 \\
\hline 15 & 2600 & 3.6 & 155 & 39.306 & 0.66 \\
\hline 16 & 2600 & 4.2 & 145 & 39.392 & 0.5 \\
\hline 17 & 2600 & 4.2 & 150 & 39.408 & 0.46 \\
\hline 18 & 2600 & 4.2 & 155 & 39.228 & 0.41 \\
\hline 19 & 3200 & 3 & 145 & 39.612 & 0.52 \\
\hline 20 & 3200 & 3 & 150 & 39.498 & 0.41 \\
\hline 21 & 3200 & 3 & 155 & 39.64 & 0.21 \\
\hline 22 & 3200 & 3.6 & 145 & 39.634 & 0.77 \\
\hline 23 & 3200 & 3.6 & 150 & 39.668 & 0.29 \\
\hline 24 & 3200 & 3.6 & 155 & 39.604 & 0.72 \\
\hline 25 & 3200 & 4.2 & 145 & 39.714 & 0.65 \\
\hline 26 & 3200 & 4.2 & 150 & 39.646 & 0.45 \\
\hline 27 & 3200 & 4.2 & 155 & 39.51 & 0.37 \\
\hline \multicolumn{4}{|c|}{ Mean } & 39.367 & 0.435 \\
\hline
\end{tabular}


Table 2. Mean values for each process parameter level.

\begin{tabular}{|c|c|c|c|}
\hline \multicolumn{4}{|c|}{ Leaner dimension: X - Direction } \\
\hline Means & Level 1 & Level 2 & Level 3 \\
\hline $\mathrm{m}_{\mathrm{A}}$ & 39.05 & 39.44 & 39.61 \\
\hline $\mathrm{m}_{\mathrm{B}}$ & 39.38 & 39.34 & 39.39 \\
\hline $\mathrm{m}_{\mathrm{C}}$ & 39.42 & 39.37 & 39.31 \\
\hline
\end{tabular}

Table 3. Mean values for each process parameter level.

\begin{tabular}{|c|c|c|c|}
\hline \multicolumn{4}{|c|}{ Deviation: (Maximum - Minimum) } \\
\hline Means & Level 1 & Level 2 & Level 3 \\
\hline $\mathrm{m}_{\mathrm{A}}$ & 0.41 & 0.41 & 0.49 \\
\hline $\mathrm{m}_{\mathrm{B}}$ & 0.31 & 0.51 & 0.48 \\
\hline $\mathrm{m}_{\mathrm{C}}$ & 0.52 & 0.34 & 0.45 \\
\hline
\end{tabular}

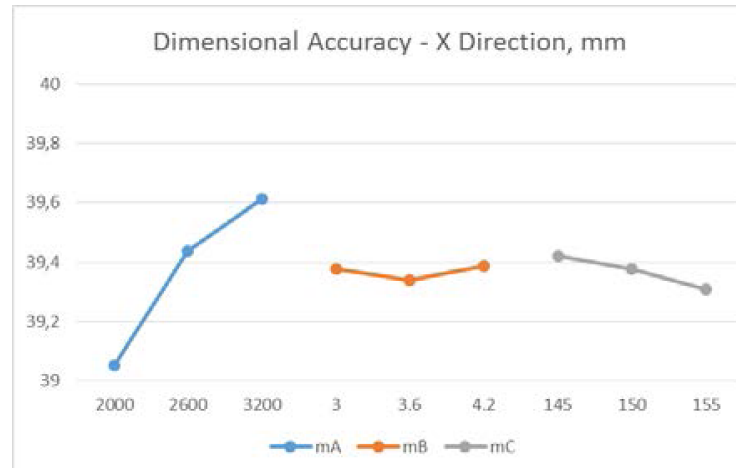

Fig. 6. ANOM Diagram (leaner dimensional accuracy).

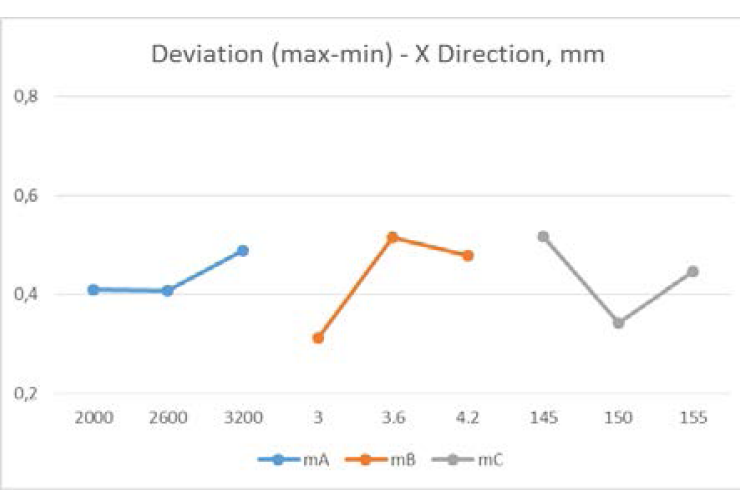

Fig. 7. ANOM Diagram (deviation of measurements).

According to the ANOM analysis and figure 6, the combination for optimizing the leaner $\mathrm{X}$ dimension is (best target value [13]); Cutting Speed: $3200 \mathrm{~mm} / \mathrm{min}$, Torch standoff distance: $3 \mathrm{~mm}$, and Arc Voltage: 145Volt. Minimization of the Deviation ([13]) is achieved when; Cutting Speed: $2000 \mathrm{~mm} / \mathrm{min}$, Torch standoff distance: $3 \mathrm{~mm}$, and Arc Voltage: 140Volt.

\subsection{Analysis of Variances - ANOVA}

Another approach to assess the different parameters impact onto the performance indicators is by using the
Analysis of Variances (ANOVA). ANOVA is also needed for estimating the error variances for the parameters effects and the error prediction variances [13].

$\mathrm{F}$ is the variance ratio, i.e. the mean square ratio due to a parameter and the mean square of the error (calculated in Tables 4 and 5). A parameter with an $\mathrm{F}$ ratio greater than 4 is considered as very important. If $\mathrm{F}$ ratio is smaller than 1 , it is considered as unimportant.

ANOVA analysis for the leaner dimension in the $\mathrm{X}$ direction shows that the variance due to all the considered parameters is about 80 percent of the total error. In this case, cutting speed is the key factor affecting about $76 \%$ the leaner dimension.

ANOVA analysis for the calculated results deviation shows that the overall variance due to all the considered parameters is about $46 \%$. This indicates that the process noise parameters cause larger variance, than the error caused due to the selected process parameters. Torch standoff distance is the most important factor affecting Deviation about $25 \%$.

Table 4. ANOVA Analysis - Leaner dimension

\begin{tabular}{|c|c|c|c|c|c|}
\hline \multicolumn{7}{|c|}{ Leaner dimension: $X$ - Direction } \\
\hline & DoF & SoS & MS & F & $\%$ \\
\hline A & 2 & 1.486 & 0.743 & 38.202 & $76.5 \%$ \\
\hline B & 2 & 0.010 & 0.005 & 0.263 & $0.5 \%$ \\
\hline C & 2 & 0.058 & 0.029 & 1.482 & $3.0 \%$ \\
\hline Total & 6 & 1.554 & & & $80.0 \%$ \\
\hline Error & 20 & 0.389 & 0.019 & & \\
\hline $\begin{array}{c}\text { Tot Error } \\
(\Sigma \text { ei })\end{array}$ & 26 & 1.943 & 0.075 & & \\
\hline
\end{tabular}

Table 5. ANOVA Analysis - Deviation

\begin{tabular}{|c|c|c|c|c|c|}
\hline \multicolumn{6}{|c|}{ Deviation: (Maximum - Minimum) } \\
\hline & DoF & SoS & MS & F & $\%$ \\
\hline A & 2 & 0.037 & 0.019 & 0.840 & $4.5 \%$ \\
\hline B & 2 & 0.210 & 0.105 & 4.714 & $25.3 \%$ \\
\hline C & 2 & 0.137 & 0.068 & 3.070 & $16.5 \%$ \\
\hline Total & 6 & 0.384 & & & $46.3 \%$ \\
\hline Error & 20 & 0.445 & 0.022 & & \\
\hline $\begin{array}{c}\text { Tot Error } \\
(\Sigma \text { ei) }\end{array}$ & 26 & 0.829 & 0.032 & & \\
\hline
\end{tabular}

\section{Conclusions}

In this work the plasma-arc cut process parameters 
impact onto the X-direction dimensional accuracy as well as onto the deviation (maximum minus minimum of five measurements) was experimentally investigated.

The optimum parameter values for the leaner dimensions on the $\mathrm{X}$ axis were; Cutting Speed: 3200 $\mathrm{mm} / \mathrm{min}$, Torch standoff distance: $3 \mathrm{~mm}$, and Arc Voltage: 145 Volt. The optimum parameter values for the deviation were; Cutting Speed: $2000 \mathrm{~mm} / \mathrm{min}$, Torch standoff distance: $3 \mathrm{~mm}$, and Arc Voltage: 140Volt.

Finally, the ANOVA analysis shows that the leaner dimension in the $\mathrm{X}$ axis is affected the most by the cutting speed (about $76 \%$ ), and the deviation is affected the most by the torch standoff distance $(25 \%)$.

\section{References}

1. S. Kalpakjian, Manufacturing Engineering and Technology, Addison-Wesley, 1995, pp.844-845.

2. S.M. Ilii , M. Coteata, A. Munteanu, "Experimental results concerning the variation of surface roughness parameter $(\mathrm{Ra})$ at plasma arc cutting of a stainless steel workpiece", International Journal of Modern Manufacturing Technologies, II/1 (2010) 31-36.

3. K. Salonitis, S. Vatousianos, "Experimental Investigation of the Plasma Arc Cutting Process", Procedia CIRP, 3 ( 2012 ) 287 - 292

4. J. Kechagias, M. Billis, S. Maropoulos, "A parameter design of $\mathrm{CNC}$ plasma-arc cutting process using robust design", Int. J. Experimental Design and Process Optimisation, 2010, 1(4):315326.

5. A. Tsiolikas, J. Kechagias, K. Salonitis, N. Mastorakis, "Optimization of cut surface quality during CNC Plasma Arc Cutting process", Int. J. of Systems Applications, Engineering \& Development, 2016, Vol 10, pp.305-308.

6. J. Kechagias, P. Stavropoulos, S. Maropoulos, K. Salonitis, "On the multi - paramenter optimization of CNC plasma-arc cutting process quality indicators using Taguchi Design of Experiments", Recent Advances in Electrical Engineering, 2014, pp.128-133.

7. B. Asiabanpour, D.T. Vejandla, J. Jimenez, C. Novoa, "Optimising the automated plasma cutting process by design of experiments", Int. J. Rapid Manufacturing, 2009, Vol. 1, No. 1, pp.19-40.

8. R. Bini, B.M. Colosimo, A.E. Kutlu, M. Monno, "Experimental study of the features of the kerf generated by a $200 \mathrm{~A}$ high tolerance plasma arc cutting system", Journal of Materials Processing Technology, 2008, Vol.196, pp.345-355.

9. J.C. Chen, Y. Li, and R.I. Cox, "Taguchi-based Six Sigma approach to optimize plasma cutting process: an industrial case study", International Journal of Advanced Manufacturing Technology, 2009, Vol.41, pp.760-769.

10. E. Gariboldi, and B. Previtali, "High tolerance plasma arc cutting of commercially pure titanium", Journal of Materials Processing Technology, 2005, Vol.160, pp.77-89.
11. A. Gullu, and U. Atici, "Investigation of the effects of plasma arc parameters on the structure variation of AISI 304 and St 52 steels", Materials \& Design, 2006 Vol.27, pp.1157-1162.

12. Q. Zhou, H. Li, F. Liu, S. Guo, W. Guo, and P. Xu, "Effects of nozzle length and process parameters on highly constricted oxygen plasma cutting arc", Plasma Chemistry \& Plasma Processing, 2008, Vol.28, pp.729-747.

13. M.S. Phadke, Quality Engineering using Robust Design, Prentice-Hall, Englewood Cliffs, NJ, 1989. 